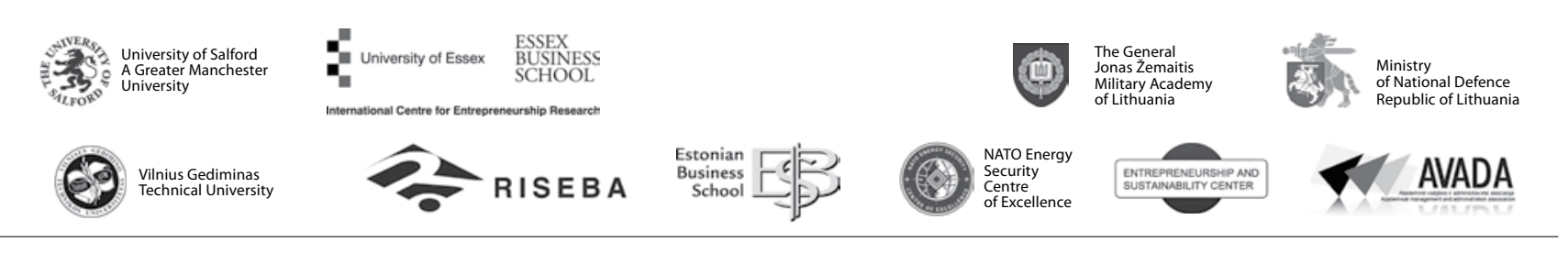

\author{
JOURNAL OF SECURITY AND SUSTAINABILITY ISSUES \\ ISSN 2029-7017 print/ISSN 2029-7025 online \\ 2017 June Volume 6 Number 4 \\ http://doi.org/10.9770/jssi.2017.6.4(9)
}

\title{
TRUST AND A SUSTAINABILITY OF THE MACROECONOMIC GROWTH INSIGHTS FROM DYNAMIC PERSPECTIVE
}

\author{
Beata Gavurova ${ }^{1}$, Zuzana Virglerova ${ }^{2}$, Frantisek Janke ${ }^{3}$ \\ ${ }^{1,3}$ Department of Banking and Investment, Faculty of Economics, \\ Technical University of Kosice, Nemcovej 32, 04001 Košice, Slovakia \\ ${ }^{2}$ Centre for Applied Economic Research, Faculty of Management and Economic, \\ Tomas Bata University in Zlín, Mostni 5139, 760 01, Zlin, Czech Republic \\ E-mails: 'beata,gavurova@tuke.sk; ${ }^{2 v i r g l e r o v a @ f a m e . u t b . c z ~(c o r r e s p o n d i n g a u t h o r) ; ~ 3 f r a n t i s e k . j a n k e @ t u k e . s k ~}$
}

Received 5 December 2016; accepted 27 March 2017

\begin{abstract}
In last two decades, several authors have already proven the existence of positive relationship between generalized trust and macroeconomic growth and this paper queues up providing the evidence based on more recent data. An analysis of sustainability of the macroeconomic growth is also very important for prediction of economic development. However, the main aim of the paper is to analyse how the impact of trust on macroeconomic growth changes upon time, trying to find the answer how fast can changes in trust and other determinants be visible in changes in economic growth of countries. For this purpose, we introduced the dynamic aspect into the "Barro-type" regression growth models used by our predecessors. We can conclude, that trust is the most dynamic growth determinant, with the impact visible after 5 years. The paper also confirmed that the higher the initial level of GDP per capita (in terms of constancy of other variables in the model), the greater the decline in the growth rate. The high level of trust also allows better implementation of effective organizational innovation and knowledge transfer within the organization, since trust is also active through the channel of building the common good.
\end{abstract}

Keywords: Social Capital, Trust, Economic Growth, Empirical Study, Linear Regression Model, Panel Data

Reference to this paper should be made as follows: Gavurova, B.; Virglerova, Z.; Janke, F. 2017. Trust and a sustainability of the macroeconomic growth insights from dynamic perspective, Journal of Security and Sustainability Issues 6(4): 637-648.

http://doi.org/10.9770/jssi.2017.6.4(9)

JEL Classification: 011,047

\section{Introduction}

The traditional macroeconomic models of growth were based on "hard" inputs such as natural resources, physical capital, changes in labour force (Solow, 1956; Swan, 1956) and later on human capital (Barro, 1991). However, even at that time, the economists understood the importance of social interactions among market actors, so called "social capital", for the functioning of the economy (Arrow, 1972). Francis Fukuyama (1995) supported the theory interconnecting moral and cultural characteristics of nations (and the level of trust) with the level of prosperity and wealth.

\section{Social capital, trust and economic growth}

Social capital positively affects the economic performance - in microeconomic perspective, moral and trustworthy social links reduces transaction costs, improves law contract enforcement or secure credit at the level 
of individual investors (Knack and Keefer, 1997; Laužikas and Dailydaitė, 2015; Bacik et al. 2015; Fuschi and Tvaronavičienè, 2016) and in macroeconomic perspective, social cohesion reinforces the democratization of governance, increases efficiency, effectiveness and compliance with the ethical principles of public administration (Putnam, 1993; Gavurova et al. 2014) with positive effects on quality of economic measures taken (Virglerova et al., 2016; Tvaronavičienè et al. 2015). According to Simionescu (2016) the increases in occupation and activity rate negatively influenced the real GDP rate while a better economic growth was achieved with higher unemployment rates.

Trust, representing the level of social capital in group of people (from community to nation), was perceived by Fukuyama (1995, p. 26) as an "expectation appearing in the community of common, honest, and cooperative behavior, based on commonly shared norms." Dehley and Newton (2003) defines trust as "faith to others that they will not harm you intentionally and knowingly if they can prevent it, and that they will take care of our interests." Bhattacharya, Devinney and Pillutla (1998) define the trust as an "expectation of positive (or negative) result that is based on the expected action of counterparty in the interaction characterized by uncertainty." Other definitions can be found in works of Deutsch (1973), Cook and Wall (1980), Carnevale a Weschler (1992, p. 473), Grunig a Hon $(1999$, p. 3) and many others. Trust differs depending on the point of view. For the purpose of this paper trust will be distinguished according to the object of trust - to whom or to what is trusted. In this context, three forms of trust need to be taken into account - firstly, interpersonal (generalized) trust, secondly, so called "thick" trust, and finally institutional (systemic) trust (Cook and Gronke, 2001; Putnam, 2000, p.137; Newton, 1997, p. 578; Luhmann, 2000). Interpersonal (generalized) trust is rooted in daily interactions between people that do not know each other (Newton, 1997; Williams, 1988). On the contrary, so-called "thick" trust is rooted in closer links and ties within the family. Institutional trust (systemic trust) represents the trust in the institutions organizing / managing the society (Cook and Gronke, 2001).

According to Fukuyama (1995) or Putnam (1993), trust in the economy is a constant component of the business contracts creation and enforcement and it is an effective mean to reduce transaction costs at all levels of society relations - social, economic and political. Transaction costs are "costs associated with the bank, insurance and financial operations, wholesale and retail exchange, and legal and accounting services" (North, 1990, p.28). Trust is essential for a problematic delegation of power - the solving of the so-called "Principal Agent Problem" is easier in trustworthy societies (Notrh, 1990). Trust also enables the solving of "collective problems" (Whiteley, 2000, p. 451). Moreover, Whiteley (2000) and Putman (1995) points out that trust allows the coordination and cooperation to achieve common benefit, helps solving the dilemma of collective action and reduces the tendency to opportunism and egoism. In economic research, the trust is therefore understood as a "lubricant" smoothing the cooperation among economic agents in the economy / society, in other words, the higher level of trust increases the efficiency of cooperation among companies, between companies and customers, between public bodies and citizens (Škarpová and Grosová, 2015; Kac et al. 2016).

The level of trust, in cooperation with other determinants of economic development, positively influences the economic performance of community, city, region, or nation (Jantoń-Drozdowska and Majewska, 2015). As an evidence, several studies have been published to support this hypothesis (Knack a Keefer, 1997; Zak a Knack, 2001, Berggren et al., 2008; Roth, 2007). Within this paper, we would like to enrich the inherited knowledge by new dynamic insights. The trust in economic growth has an huge impact also on business environment. According to Belás et al. (2015) the optimism of economic entities is essential for the proper functioning of the whole economic system. This paper is focused on an analysis of the impact of trust on macroeconomic growth changes during the period from 1995 to 2008. The results are original, because of understanding the dynamics of influence of different economic growth determinants in "stable" economic times with the lowest systematic failures and external shocks.

\section{Methodology, goals and hypotheses}

The main aim of the paper is to analyse how the impact of trust on macroeconomic growth changes upon time, trying to find the answer how fast can changes in trust and other determinants be visible in changes in economic growth of countries. The concept of research is thus based on a number of empirical studies based on the so-called Barro 
endogenous growth model (Barro, 1991; Barro and Sala-i-Martin, 1992) of countries that considers the effects of the determinants of economic development to the growth rate of macroeconomic performance (the growth rate typically measured by gross domestic product per capita). The basis of the neoclassical growth model are the works of 2 authors: Solow (1956) and Swan (1956). Their model is based on the neoclassical production function, based on the law of diminishing marginal revenue by exogenous factors - saving, population growth and technological change; he pointed to the convergence of income per capita, which would mean the finality of living standards (Inglehart, 1997). The inability of the model to describe long-term economic development motivated many economists in the 80 s of the 20th century to construct models of endogenous growth (Romer, 1986, 1990; Lucas, 1988; Barro, 1991; Mankiw, Romer and Weil, 1992; Barro and Sala-i-Martin, 2004). They work with a broader understanding of the concept of capital - comprising human capital, not covered by the law of diminishing revenues border. Barro (1991) identified a set of other variables that are essential for long-term economic growth. Adding more variables into the Barro model we call "Barro-type" regression. We explore the following working hypothesis:

Working hypothesis 1: level of trust in the country has a positive effect on economic growth.

Testing this hypothesis will be made by using the regression model, the authors use in Berggren et al. (2008) and Roth (2006), which builds on the work of authors (Knack and Keefer 1997; Forbes 2000; Zak and Knack 2001) based on generally registered model, shown in Equation 1:

Working task 1.1: to quantify the impact of trust on economic growth in a regression model.

\section{Specification of the model}

As part of the analysis a linear regression model will be used. It will have the following form, where $i$ represents a specific country:

$$
y_{i, t_{n}}=\alpha_{i}+\beta_{1} Y_{i, t_{0}}+\beta_{2} I_{i, t_{0}}+\beta_{3} H_{i, t_{0}}+\beta_{4} T_{i, t_{0}}+\varepsilon_{i}
$$

where:

$y_{i, t_{n}} \quad$ is the average annual growth of GDP per capita term, since $\mathrm{t}_{0}$ to $\mathrm{t}_{\mathrm{n}}$,

$Y_{i, t_{0}} \quad$ is the term of the natural logarithms of income measured by the absolute level of GDP per capita in $\mathrm{t}_{0}$,

$I_{i, t_{0}} \quad$ is the term of physical capital measured by the price level of investment in $\mathrm{t}_{0}$,

$H_{i, t_{0}} \quad$ is a term of the human capital measured by Average Years of Schooling Attained of the working population in $\mathrm{t}_{0}$,

$T_{i, t_{0}} \quad$ is a term of the trust (social capital) measured by levels of trust to other people in $\mathrm{t}_{0}$,

$\varepsilon_{i} \quad$ is the random error component.

We assume the following relationships in the model:

- $Y_{i, t_{0}}$ - the level of initial macroeconomic performance has a negative relationship with a growth rate as shown by many empirical studies, when in the very long run growth rate of countries converge to the "equilibrium" value of the growth rate. Less developed countries are growing faster because of the existence of the law of declining border revenues from physical capital,

- $I_{i, t_{0}}$ - we expect a negative correlation at the price level of investment with the growth rate, relatively expensive capital means that investments are less favorable - the expected profit is lower and so is the country less attractive to investors which adversely affects the level of investment in the country and has a negative impact on the growth rate,

- $H_{i, t_{0}}$ - human capital is positively linked to the level of the growth rate, since the growth of education of the labor force increases the productivity. This stems from the work of Barro (1991), where the inclusion of hu- 
man capital, not covered by the law on declining border revenues (as opposed to physical capital) into models of economic growth solved the problem of increasing living standards in rich countries, which should, according to the traditional model (Sollow, 1956; Swan, 1956) stagnate,

- $T_{i, t_{0}}$ - trust is positively linked to growth rates, by reducing transaction costs and more efficient solutions to collective social problems in the country. Reducing the transaction cost increases productivity and hence growth rates.

The data used in the regression are cross-cutting and have natural character - we abstract from the temporal aspect, and observations are collected for a sample of countries (for each of the countries in the sample, just one observation within a 5-year period), which is analogous to the thesis of Knack and Keefer (1997), Zak and Knack (2000), Roth (2006) and Berggren et al. (2008). Regression analysis, moreover, will be carried out on a sample of more recent data on the level of trust.

However, the main difference is the time adaptation of all variables entering the regression model of the measured level of trust. Previous work used explanatory variables at the beginning of the reporting period to the variable for the explanation of medium-term average rate of economic growth - the level of trust which is taken from any moment during the period where there is a possibility of the presence of reverse causality between growth and trust. Knack and Keefer (1997) and Zak and Knack (2000) advocated with the fact that trust highly correlated between decades (correlation coefficient of 0.9 ) and hence the level of trust is relatively stable. In our approach the level of trust is the central variable (for the irregular measurement) at time $t_{0}$ and other explanatory variables are matched with the variable - they are also measured in $t_{0}$. The exception is explained by the variable which is the average annual growth rate at various time intervals from $t_{0}$. The first step will be to construct a model explaining the average annual growth of GDP per capita for the 10-year time horizon (based on work Berggren et al., 2008), but then the results of the model on the short medium-term basis will be analyzed. The time window which the economic growth will be calculated for (the dependent variable) will thus change $\left(t_{0}\right.$ to $t_{1} t_{0}$ to $t_{2}, \ldots, t_{0}$ to $\left.t_{12}\right)$, independent variables will still be associated with the year $t_{0}$ - the year in which the data was measured on the level of trust. The approach is graphically presented in Figure 1 (below).

The proposed design of regression models with changing horizon, which the average annual growth rate of GDP per capita is calculated for, enable us to go beyond previous studies performed following additional work task.

Working task 1.2: verify the changes in the impact of trust on economic growth in a changing-term of economic growth.

\section{A. Approach of previous empirical studies}

\begin{tabular}{|c|c|c|c|c|c|c|c|c|c|c|c|c|c|c|}
\hline & 1990 & 1991 & 1992 & 1993 & 1994 & 1995 & 1996 & 1997 & 1998 & 1999 & 2000 & 2001 & 2002 & 2003 \\
\hline Argentina & $t_{0}$ & & & & & & & & & & $t_{10}$ & & & \\
\hline Belgium & $t_{0}$ & & & & & & & & & & $t_{10}$ & & & \\
\hline Denmark & $t_{0}$ & & & & & & & & & & $t_{10}$ & & & \\
\hline
\end{tabular}

\section{B. Our approach}

\begin{tabular}{|c|c|c|c|c|c|c|c|c|c|c|c|c|c|c|}
\hline & 1995 & 1996 & 1997 & 1998 & 1999 & 2000 & 2001 & 2002 & 2003 & 2004 & 2005 & 2006 & 2007 & 2008 \\
\hline Argentina & & & & $t_{0}$ & & & & & & & & & & $t_{10}$ \\
\hline Belgium & $t_{0}$ & & & & & & & & & & $t_{10}$ & & & \\
\hline Denmark & & & $t_{0}$ & & & & & & & & & & $t_{10}$ & \\
\hline
\end{tabular}

\section{Legend}

Year of Trust data gathering
Year of economic growth data gathering (from $t_{0}$ to $t_{10}$ )
$t_{0} \quad$ Year of other independent variables gathering (except Trust)

Figure 1. Comparison of different approaches to data modelling - our approach vs. previous studies 


\section{The used data}

As part of the analysis the following secondary data will be used to express the variables in the linear regression model. It is important to say, that our aim was to study the relationships on as stable economic period as possible. In this regard, the period from 1995 to 2008 was chosen (with most of the cases from 1996 to 2006). To understand the dynamics of influence of different economic growth determinants, the "stable" economic times with the lowest systematic failures or external shocks possible is desirable. Choosing this timeframe, our aim was to avoid the turbulent economic times after financial crisis beginning in 2008, what would definitely affect the elaborated analyses. Although, it might be very interesting to study how the economic crisis influenced the relationship between trust and economic growth, this is not the purpose of this paper.

\section{Measurement of economic performance}

The analysis will use real gross domestic product per capita, expressed in US dollars at constant 2005 prices for the measurement of economic performance of countries obtained by expenditure approach and converted using purchasing power parities. The part of income attributable per capita, constant prices and purchasing power parity conversion were selected for the purpose of carrying out the possibility of country comparison without affecting the size of the country and inflation, based on the real exchange rate. Data are secondary in nature and derived from the Penn World database, Table 7.1 (Heston et. Al, 2012) - item „,rgdpch” - PPP Converted GDP Per Capita, Chain Series, at 2005 constant prices. This indicator is in contrast to the level of trust measured every year. In the linear regression model the average annual growth in gross domestic product per capita in the various annual intervals from $t_{0}$ will be used - year the level of trust was measured in.

\section{The level of current income levels}

Current income level of the country will be calculated through the natural logarithm of real gross domestic product per capita. As in the previous case, the nature of data is secondary, from Penn World database, Table 7.1 (Heston et al., 2012) - item „rgdpch” - Converted PPP GDP per capita Chain Series, at constant 2005 prices. Logarithm of the variable was chosen in order to exclude the exponential form of growth of economies, through which the countries with high absolute levels of GDP per capita grow with higher absolute increments (Michener, 2003).

\section{Investments}

The component of investments will be measured by the price level of investments for the country from $t_{0}$. This indicator was obtained from the Penn World database, Table 7.1 (Heston et al., 2012) and its level compares the price level of investment goods with the overall level of prices in the USA (the price level in the USA $=100$ ). The level of this indicator can determine the status of the country compared to the "reference" value in the given year. It also reflects the differences between countries due to local conditions, such as tariffs, government regulations, exchange rates, etc.

\section{Interpersonal trust}

To measure the level of interpersonal trust in the countries, secondary data obtained from surveys of the World Values Survey (2009) were used. For the needs of our research, we have processed the answers on the question: "Generally speaking, would you say that most people can be trusted or that you can't be too careful in dealing with people?" with two possible answers: "Most people can be trusted" or "Can't be too careful". In further analysis the level of interpersonal trust in the year " $t$ " is a percentage of people within the country in the year " $T$ " intended, who answered that people can be trusted. Mathematically speaking, the level of trust in the people is calculated as a share of the answers "people can be trusted" to the total number of responses in a given year in the given country.

It needs to be mentioned, that WVS surveys are not carried out for each country for the continuous time period. Thus, unbalanced panel data have been used in the research. The data covers the survey wave conducted from 1995 - 1998, respecting the choice of stable economic period regarding GDP per capita data. 


\section{Human capital}

To measure the level of human capital in our case, the variable used by authors Berggren et al. (2008) and Roth (2006), was used - average school attendance years in population that finished its studies and has the age above 15 years (gender regardless). Data are secondary in nature and were obtained from the database of Barro-Lee Dataset (Barro and Lee, 2010) - the variable "Average Years of Schooling Attained." The information in this database is collected at 5-year intervals, always at the beginning of the decade and in its center (for example $1990,1995,2000$, etc.). For each observation is selected a value from the year nearest to $t_{0}$ (if, for example $t_{0}$ is 1996, data about the average school attendance from year 1995 is used). Merely this indicator causes the inaccuracy to the model, as the level of education is not from the year $t_{0}$ (this inaccuracy will cover $3 / 4$ of the sample, as only $1 / 4$ of observations will correctly work with the level of attendance from 1995). One half of the sample will be given the level of attendance from 1 year delay compared to $t_{0}$ (in sum, up to $3 / 4$ of the sample will work only with inaccuracy caused by a one year delay). In addition, the education level is quite stable variable over years (more stable than the trust variable, what supports our approach to design the data modelling in comparison to authors of previous empirical studies). Below, the "stem-and-leaf" graphs for the average annual change in Trust and in Average years of schooling attained for 1990-1995 are presented. The time deviation of trust in previous researches was in many cases significantly higher, because the level of trust was collected on a horizon of, for example, 10 years - in our case, the time deviation is maximum 2 years (plus or minus). Based on the above, the possible inaccuracy caused by the level of average school attendance measured this way is smaller than the uncertainty caused by the delay (compared to $t_{0}$ ) in the measurement of trust from the studies (Knack and Keefer 1997; Zak and Knack 2001; Roth 2006 Berggren et al., 2008).
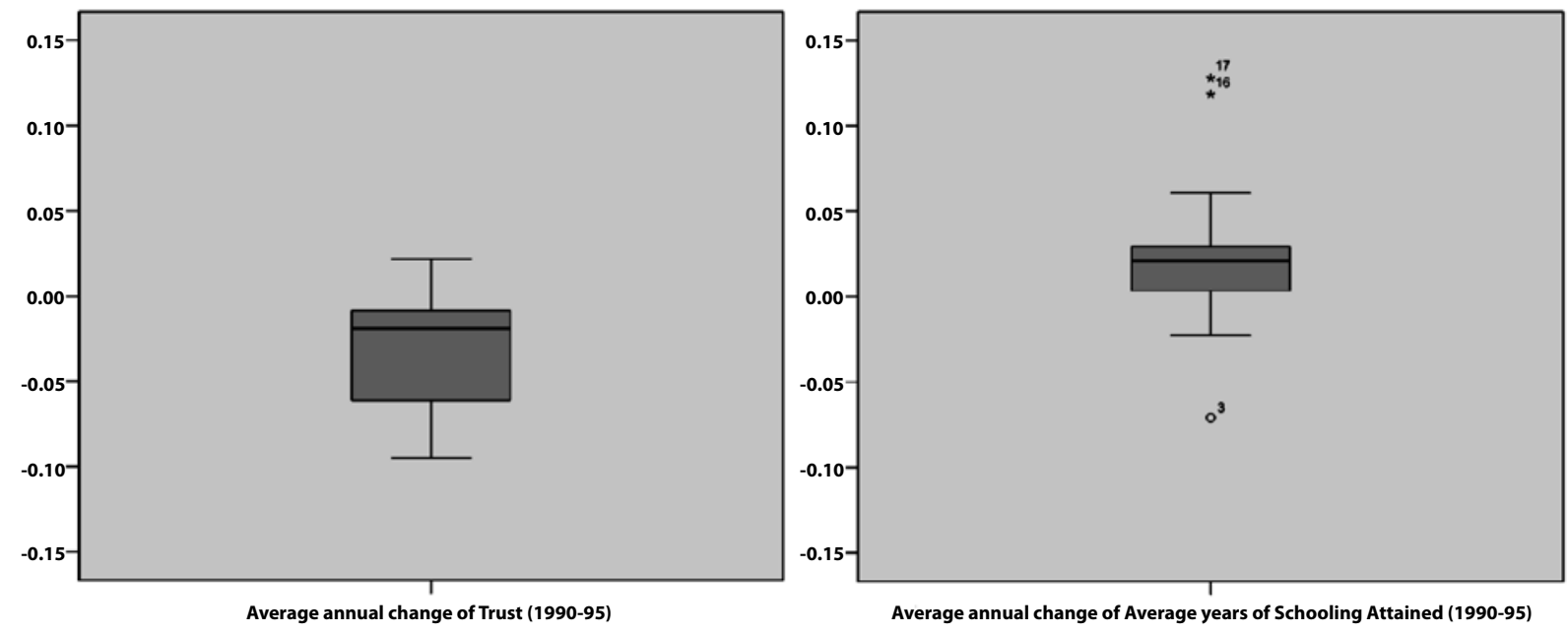

Figure 2. Comparison of „Stem-and-Leaf“ graphs of average annual growth of trust and school attendance between 1990-1995

\section{Sample description}

The regression analysis will use a sample of 47 observations from a 5-year period around the year 1995. As it was mentioned previously, the key variable for data collection is the level of trust in the irregular nature of the collection. From the year when the trust was measured $\left(\mathrm{t}_{0}\right)$ are all the other variables derived - all other explanatory variables are also from $t_{0}$ (except of the indicator of average school attendance, where in $3 / 4$ of the sample the delayed data will be used). All explanatory variables are thus concentrated around the year 1995, obtained in the $5^{\text {th }}$ wave of the World Values Survey Survey (2009) carried out between 1994 and 1998. The sample is represented by countries from all continents.

The highest average annual growth in GDP per capita since $\mathrm{t}_{0}$ in a 10 -year period reached $10.43 \%$ in Armenia, while the smallest growth of $0.802 \%$ was in Colombia. Thus, no country on this 10 -year term did not record a decline, although dips were present. The average value for this group of countries is $2.937 \%$. The highest level of prosperity (GDP per capita) is in Norway (40381.27 USD, which is a logarithmic adjustment after 10.61), 
again, the lowest is in Bangladesh (800.24 USD, 6.68 after logarithmic).

The largest share of people (65.3\%) with the answer that other people can be trusted was in Norway, the lowest level of trust has been measured in Brazil, only $2.8 \%$. Country with the lowest average school attendance - only 1.22 years - is Nigeria. The highest attendance is in USA - 12.630 years. The lowest price level of investments is in India - it is given at the level of $34.188 \%$ of the price level of USA. The highest price level of investments in in Japan $-145.766 \%$.

\section{Results and discussion}

At the beginning, according to the equation No. 1 a model of an average annual growth of GDP per capita for the 10-year period from $t_{0}$ after year $t_{10}$ will be created (according to Berggren et al., 2008, note: Knack and Keefer, 1997 used a 12-year period). Parameters of the regression model using cross-sectional data described above are estimated by the method of least squares.

Based on the results of executing regression modeling, the model predicting average annual growth of GDP per capita for the country can be written in the following format (Equation 2):

$$
\mathrm{y}_{t_{10}}=0,137224-0,015443 \ln Y_{t_{0}}-0,000265 I_{t_{0}}+0,005172 H_{t_{0}}+0,046428 T_{t_{0}}
$$

There are the following relationships between the explaining and explanatory variables:

$\ln Y_{\mathrm{t}_{0}}$ - negative relationship (coefficient -0.0154 , standard coefficient -0.694), and this relationship is statistically significant at the significance level 0,001 ,

$I_{\mathrm{i}, \mathrm{t}_{0}}$ - negative relationship (coefficient -0.00026 , standard coefficient -0.305 ) and this relationship is statistically significant at the significance level 0,053 ,

$H_{\mathrm{i}, \mathrm{t}_{0}}$ - positive relationship (coefficient +0.0052 , standard coefficient 0.578 ) and this relationship is statistically significant at the significance level 0,004 ,

$T_{\mathrm{i}, \mathrm{t}_{0}}$ - positive relationship (coefficient +0.0464 , standard coefficient 0.284 ) and this relationship is statistically significant at the significance level 0,020 .

In application of the "2-sigma" rule the direction of the impact (positive or negative) of each explanatory variable on the growth rate remains unchanged (the regression coefficient of trust has the lowest border of $95 \%$ confidence interval at +0.0104 ).

When comparing the standardized coefficient, it is seen that the greatest impact (0.694) on the growth rate in the ten years' period from $t_{0}$ has the initial level of GDP per capita, followed by members of the human capital $(+0.578)$, member of the investment (-0.305) and member of the trust is to last place $(0.284)$.

\section{Trust and economic growth - moving time window}

As a complement to the models described, we will notice a change in the results of regression models depending on the replaced time horizon which the average annual growth rate of GDP per capita is calculated for. It will thus compile additional 9 models, with a time horizon of explaining variable will be in the extent $\mathrm{t}_{0}, \mathrm{t}_{1}$ (annual period) to $T_{0}, T_{9}$ (nine-year period). The results of the regression are shown in the tables below.

When looking at the factors (Figure 3), we see that in the three-year time horizon there are the same relationships (positive and negative) between explaining variables and explanatory variables, as was the case with 10 -year term. 


\begin{tabular}{|c|c|c|c|c|c|c|c|c|c|c|}
\hline \multirow{3}{*}{ dependent variable } & \multicolumn{10}{|c|}{ Average annual growth of GDP per capita over the period from $t_{0}$ to $t_{n}$} \\
\hline & \multicolumn{2}{|c|}{$t_{0}, t_{1}$} & \multicolumn{2}{|c|}{$t_{0}, t_{2}$} & \multicolumn{2}{|c|}{$t_{0,}, t_{3}$} & \multicolumn{2}{|c|}{$t_{0, t_{4}}$} & \multicolumn{2}{|c|}{$t_{0, t_{5}}$} \\
\hline & B & $\begin{array}{l}\text { stand. } \\
\text { coeff. }\end{array}$ & B & $\begin{array}{l}\text { stand. } \\
\text { coeff. }\end{array}$ & B & $\begin{array}{l}\text { stand. } \\
\text { coeff. }\end{array}$ & B & $\begin{array}{l}\text { stand. } \\
\text { coeff. }\end{array}$ & B & $\begin{array}{l}\text { stand. } \\
\text { coeff. }\end{array}$ \\
\hline (constant) & $\begin{array}{l}.122^{* * *} \\
(.0454)\end{array}$ & & $\begin{array}{c}.049 \\
(.0408)\end{array}$ & & $\begin{array}{c}.024 \\
(.0482)\end{array}$ & & $\begin{array}{c}.031 \\
(.0401)\end{array}$ & & $\begin{array}{c}.062 \\
(.0379)\end{array}$ & \\
\hline GDP per capita in to & $\begin{array}{l}-.012 \\
(.0082)\end{array}$ & -.355 & $\begin{array}{c}-.003 \\
(.0069)\end{array}$ & -.116 & $\begin{array}{c}-.001 \\
(.0078)\end{array}$ & -.055 & $\begin{array}{c}-.002 \\
(.0065)\end{array}$ & -.096 & $\begin{array}{c}-.007 \\
(.0060)\end{array}$ & -.327 \\
\hline $\begin{array}{l}\text { The price level of } \\
\text { investment in to }\end{array}$ & $\begin{array}{c}.000 \\
(.0002)\end{array}$ & .022 & $\begin{array}{c}.000 \\
(.0002)\end{array}$ & -.068 & $\begin{array}{c}.000 \\
(.0002)\end{array}$ & -.153 & $\begin{array}{l}.000 * * \\
(.0001)\end{array}$ & -.314 & $\begin{array}{l}.000 * * * \\
(.0001)\end{array}$ & -.318 \\
\hline $\begin{array}{l}\text { The average school } \\
\text { attendance in to }\end{array}$ & $\begin{array}{c}.002 \\
(.0030)\end{array}$ & .129 & $\begin{array}{c}-.001 \\
(.0024)\end{array}$ & -.043 & $\begin{array}{c}.001 \\
(.0024)\end{array}$ & .057 & $\begin{array}{c}.002 \\
(.0021)\end{array}$ & .206 & $\begin{array}{l}.004 * * \\
(.0019)\end{array}$ & .427 \\
\hline Level of trust in $t_{0}$ & $\begin{array}{c}.046 \\
(.0356)\end{array}$ & .183 & $\begin{array}{l}.080 * * \\
(.0322)\end{array}$ & .375 & $\begin{array}{l}.077 * * * \\
(.0261)\end{array}$ & .405 & $\begin{array}{l}.076 * * * \\
(.0221)\end{array}$ & .445 & $\begin{array}{l}.075^{* * *} \\
(.0200)\end{array}$ & .448 \\
\hline Number of observations & \multicolumn{2}{|c|}{47} & \multicolumn{2}{|c|}{47} & \multicolumn{2}{|c|}{47} & \multicolumn{2}{|l|}{47} & \multicolumn{2}{|l|}{47} \\
\hline $\mathbf{R}^{2}$ & \multicolumn{2}{|c|}{.071} & \multicolumn{2}{|c|}{.106} & \multicolumn{2}{|c|}{.142} & \multicolumn{2}{|c|}{.245} & \multicolumn{2}{|l|}{.373} \\
\hline \multicolumn{11}{|l|}{ ANOVA } \\
\hline F & \multicolumn{2}{|c|}{0.805} & \multicolumn{2}{|c|}{1.249} & \multicolumn{2}{|c|}{1.743} & \multicolumn{2}{|c|}{3.411} & \multicolumn{2}{|c|}{6.237} \\
\hline Sig. & \multicolumn{2}{|c|}{.529} & \multicolumn{2}{|c|}{.305} & \multicolumn{2}{|c|}{.159} & \multicolumn{2}{|c|}{.170} & \multicolumn{2}{|c|}{.000} \\
\hline n-1 & \multicolumn{2}{|c|}{46} & \multicolumn{2}{|c|}{46} & \multicolumn{2}{|c|}{46} & \multicolumn{2}{|c|}{46} & \multicolumn{2}{|l|}{46} \\
\hline df & \multicolumn{2}{|l|}{42} & \multicolumn{2}{|l|}{42} & \multicolumn{2}{|c|}{42} & 42 & & 42 & \\
\hline
\end{tabular}

\begin{tabular}{|c|c|c|c|c|c|c|c|c|c|c|}
\hline \multirow{3}{*}{ dependent variable } & \multicolumn{10}{|c|}{ Average annual growth of GDP per capita over the period from to to $t_{n}$} \\
\hline & \multicolumn{2}{|c|}{$t_{0, t_{6}}$} & \multicolumn{2}{|c|}{$t_{0,}, t_{7}$} & \multicolumn{2}{|c|}{$t_{0, t 8}$} & \multicolumn{2}{|c|}{$t_{0, t_{9}}$} & \multicolumn{2}{|c|}{$t_{0,} t_{10}$} \\
\hline & B & $\begin{array}{l}\text { stand. } \\
\text { coeff. }\end{array}$ & B & $\begin{array}{l}\text { stand. } \\
\text { coeff. }\end{array}$ & B & $\begin{array}{l}\text { stand. } \\
\text { coeff. }\end{array}$ & B & $\begin{array}{l}\text { stand. } \\
\text { coeff. }\end{array}$ & B & $\begin{array}{l}\text { stand. } \\
\text { coeff. }\end{array}$ \\
\hline (constant) & $\begin{array}{l}.095^{* * *} \\
(.0351)\end{array}$ & & $\begin{array}{l}.116^{* * *} \\
(.0338)\end{array}$ & & $\begin{array}{l}.130 * * * \\
(.0339)\end{array}$ & & $\begin{array}{l}.137 * * * \\
(.0336)\end{array}$ & & $\begin{array}{l}.137 * * * \\
(.0314)\end{array}$ & \\
\hline GDP per capita in $t_{0}$ & $\begin{array}{l}-.012 * * \\
(.0056)\end{array}$ & -.506 & $\begin{array}{c}-.015 * * * \\
(.0055)\end{array}$ & -.622 & $\begin{array}{l}-.016 * * * \\
(.0052)\end{array}$ & -.699 & $\begin{array}{l}-.016 * * * \\
(.0051)\end{array}$ & -.720 & $\begin{array}{l}-.015 * * * \\
(.0048)\end{array}$ & -.694 \\
\hline $\begin{array}{l}\text { The price level of } \\
\text { investment in } t_{0}\end{array}$ & $\begin{array}{l}.000 * * \\
(.0001)\end{array}$ & -.295 & $\begin{array}{l}.000 * * \\
(.0001)\end{array}$ & -.278 & $\begin{array}{l}.000 * * \\
(.0001)\end{array}$ & -.260 & $\begin{array}{l}.000 * * \\
(.0001)\end{array}$ & -.265 & $\begin{array}{l}.000 * * * \\
(.0000)\end{array}$ & -.305 \\
\hline $\begin{array}{l}\text { The average school } \\
\text { attendance in to }\end{array}$ & $\begin{array}{l}.005^{* * *} \\
(.0018)\end{array}$ & .509 & $\begin{array}{l}.006 * * * \\
(.0017)\end{array}$ & .601 & $\begin{array}{l}.006^{* * *} \\
(.0016)\end{array}$ & .608 & $\begin{array}{l}.005^{* * *} \\
(.0016)\end{array}$ & .584 & $\begin{array}{l}.005^{* * *} \\
(.0015)\end{array}$ & .578 \\
\hline Level of trust in $t_{0}$ & $\begin{array}{l}.072 * * * \\
(.0187)\end{array}$ & .415 & $\begin{array}{l}.064 * * * \\
(.0191)\end{array}$ & .360 & $\begin{array}{l}.056^{* * *} \\
(.0179)\end{array}$ & .333 & $\begin{array}{l}.050 * * * \\
(.0175)\end{array}$ & .305 & $\begin{array}{l}.046^{* * *} \\
(.0178)\end{array}$ & .284 \\
\hline Number of observations & \multicolumn{2}{|c|}{47} & \multicolumn{2}{|c|}{47} & \multicolumn{2}{|c|}{47} & \multicolumn{2}{|c|}{47} & \multicolumn{2}{|c|}{47} \\
\hline $\mathrm{R}^{2}$ & \multicolumn{2}{|c|}{.499} & \multicolumn{2}{|c|}{.486} & \multicolumn{2}{|c|}{.510} & \multicolumn{2}{|c|}{.512} & \multicolumn{2}{|c|}{.525} \\
\hline \multicolumn{11}{|l|}{ ANOVA } \\
\hline F & \multicolumn{2}{|c|}{10.447} & \multicolumn{2}{|c|}{9.939} & \multicolumn{2}{|c|}{10.920} & \multicolumn{2}{|c|}{11.017} & \multicolumn{2}{|c|}{11.614} \\
\hline Sig. & \multicolumn{2}{|c|}{.000} & \multicolumn{2}{|c|}{.000} & \multicolumn{2}{|c|}{.000} & \multicolumn{2}{|c|}{.000} & \multicolumn{2}{|c|}{.000} \\
\hline $\mathrm{n}-1$ & \multicolumn{2}{|c|}{46} & \multicolumn{2}{|c|}{46} & \multicolumn{2}{|c|}{46} & \multicolumn{2}{|c|}{46} & \multicolumn{2}{|c|}{46} \\
\hline df & \multicolumn{2}{|c|}{42} & \multicolumn{2}{|l|}{42} & \multicolumn{2}{|c|}{42} & 42 & & 42 & \\
\hline
\end{tabular}

Figure 3. Trust and economic growth - the results of regression models for time horizon of 1-10 years from $\mathrm{t}_{0}{ }^{1}$

\footnotetext{
1 Significant at the significance level of $0.1(*), 0.05(* *)$ and $0.01(* * *)$. In brackets the White's standardized deviations are presented (due to the presence of heteroskedasticity based on Breusch-Pagan test the robust estimate was used). All regressions satisfy the condition of absence of multicollinearity (based on the values of VIF) and normality levels (based on Shapiro-Wilk test).
} 
The initial level of income and price levels of investment have a negative coefficient, education and trust on the contrary, a positive coefficient. The model with the three-year average growth rate of GDPpC trust is the only statistically significant variables, on a four-year term the price level of investment is added to it. In the 5-year term for these variables education is increasing, but till the six-year term are all variables at least at the level of significance equaling to 0.05 statistically significant.

Regarding the standardized regression coefficients, we see that the coefficient of trust is growing after a 5-year horizon, and from that moment it is dropping, the maximum impact on the growth rate is in the fifth year from the time $t_{0}$. In education we see a growing progress with an increasing time horizon for the eighth year, after which is the standardized coefficient slightly falling. Education thus acts in a slight delay compared with trust. Investments are across the horizon surveyed remaining relatively stable, although the maximum is recorded in the fifth year. With regard to the initial level of income of the country, the impact is stronger for the longer term, as the value of the standardized coefficient increases with the addition of years. It is interesting, that when in the explanatory model of the ten-year average growth GDPpC is the trust the least influential explanatory variable, in a 5-year horizon is the situation the opposite - trust has the highest standardized coefficient.

It can be assumed that higher the initial level of GDP per capita (in terms of constancy of other variables in the model), the greater the decline in the growth rate. This confirms the findings of many empirical studies based on the so-called. "Barro" regressions (Barro, 1991 and successors), which show that less developed (less rich) countries grow faster, because in those countries there is untapped potential of available labor - e.g. adding units of capital in a poor country will make an increase of the product of a greater extent than it would make in a rich country. This phenomenon is known as $\beta$ - convergence. Due to the logarithmic transformation of GDP per capita within the modeled regression is possible to quantify the impact of the variable per capita GDP on the growth rate - for example by increasing GDP per capita of 10\% (from 5000 USD to 5500 USD, or from 20000 USD to 22000 USD) when the condition of constancy of other variables is fulfilled, a decline in the growth rate of GDP per capita by 0.1471875 percentage points can be expected. Within the reporting timeframe, this variable is statistically significant from 6-year-term growth rate of GDPpC.

There were new findings made on a new sample and created by a model with higher accuracy due to harmonization of observations with the year of measurement in our study of the key variable - the levels of trust confirm the findings from previous empirical research (Knack and Keefer 1997; Zak and Knack 2001; Berggren 2008; Roth, 2006), although these could not demonstrate statistical significance for all variables at the necessary level (e.g. in Roth, 2006, therefore, excluded from the learning model). We managed to point out the significance of all selected variables in our models. The reason why some of the searches conducted until now have not been able to offer all the variables to be statistically significant is is probably due to the chosen time horizon. The results show the suitability of this model at least 5 years of economic growth, although this term is the initial income level in the country not significant yet - the 6-year to 10-year horizon model includes such variables as statistically significant.

The time design of the model used by us also allowed the study of changes in the results of the model (with particular emphasis on the impact of trust) at varying time horizon of the explaining variable. The model constructed gets a statistically significant explanatory variable in a time horizon of 2 years since $\mathrm{t}_{0}$ and it is the level of trust. Trust is only the first variable from the used explanatory variables that have significant impact on economic growth. Then, the price level, the average schooling, followed by the initial level of income of the country are gradually added with the extending time horizon. At nearly the whole monitored horizon of the average growth rate of GDP per capita (except for the first two years) the variables are monitored in the same direction - trust is positive, the initial income is negative, the price level of investment is negative and education is positive. The model is therefore useful to predict the rate of growth for the medium term, when the growth in cleared from short-term fluctuations, which is the intended timeframe when constructing the so-called. "Barro regressions" (Barro, 1991 and successors). Methodologically most comparable (except for a different point in time captured by data of trust and average school attendance) is a model of the authors Berggren et al. (2008). They also use 10-year time window and it differs from our research only in sample. The model is constructed 
on data between 1990 and 2000. The difference in the coefficient belonging to trust in our case is 0.464 , at the given authors it is higher $(0,062)$. It is questionable whether is this shift caused by the design of the model, but the truth is that to trust were given higher coefficients in a shorter time period, so, if the previous models used a lot of values of trust from the middle of the examined period, it could overestimate the impact of trust on the predicted growth rate.

\section{Conclusions}

The main aim of the paper was to analyse how the impact of trust on macroeconomic growth changes upon time. First, we will sum up whether in the context of the results the expected relationship between the explanatory variables and the average growth rate GDPp was fulfilled. As stated above the amount of initial macroeconomic performance $\left(\ln \mathrm{Y}_{\mathrm{t}_{0}}\right)$ has negative correlation with the growth rate (the ten-year term, the growth rate is a factor of -0.0154). The higher the initial level of GDP per capita (in terms of constancy of other variables in the model), the greater the decline in the growth rate.

The price level of investment has a negative relationship with the growth rate $\left(I_{t_{0}}\right)$ (coefficient of 0.000265 to 10-year horizon) - relatively expensive capital means less investments, which negatively affects the rate of growth. Any increase in price levels of capital by 1 percentage point compared with the price level in the reference member state will decrease the average growth rate within a ten-year term of 0.0265 percentage points. This relationship is statistically significant from the 4-year-term growth rate.

Human capital $\left(\mathrm{L}_{t_{0}}\right)$ is positively linked to the level of growth rate (10-year term, the growth rate is a factor of 0.00517) - with the growth of education of the labor force its productivity is increasing, which has a positive impact on economic growth. Any increase of the average school attendance by 1 year will increase the average 10 -year rate of increase of 0.517 percentage points. This confirms the findings from the work of many authors studying the impact of human capital on economic growth (Barro, 1991 and successors). This relationship is statistically significant from a 5-year horizon and 10-year horizon (which was the longest horizon in this survey).

The main variable researched was trust $\mathrm{D}_{t_{0}}$. In its case we confirmed the expected positive impact on the average growth rate (10-year term, the growth rate is a factor of 0.046428$)$. When the condition of no other variable changed in the model was fulfilled, any increase in the level of trust of 10 percentage points will increase the average annual growth rate for 10 -year term of 0.46428 percentage points. Our working hypothesis 1.1 "Higher level of trust between people supports the economic growth" will not be denied. Economic agents are using the sources more effectively because they invest less time and money into protection against unexpected behavior of counterparties, or situation abuse in its favor. The high level of trust also allows better implementation of effective organizational innovation and knowledge transfer within the organization, since trust is also active through the channel of building the common good. Trust therefore acts as „lubricant“ which makes interaction between economic agents easier more effective which increases the efficiency of use of available resources, resulting in higher economic growth.

Another interesting finding is the fact that trust is present even in the short term, unlike other variables the impact of which is significant only in the medium term. The fastest way to change the level of the rate of growth is by changes in the level of trust. In shorter term ( 5 years) trust has the greatest impact among all selected variables. In a larger timeframe the impact of trust on economic growth is overshadowed by other variables. Trust is therefore connected to short time periods - to the so called Kitchin's cycles, ore to do with short called. Kitchin's cycles, and other variables with the middle periods - the Junglar cycles. Impact of trust on the pace of growth "culminates" in a 5-year term, so, the changes in the level of trust does not affect the country immediately, but in a period of 5 years. Agents need time, until their deteriorating / improving experience with the behavior of counterparties, resp. changes in the standards governing the operation of the company reflect in their decisions and affect relationships with other agents. When the company, for example, increases the protection of property rights (through increased law enforcement), it is likely that these standards will be prudent to reduce practices endangering individual rights. Individuals will feel less vulnerable and thus there is a gradual increase 
of trust in the company. This change will not close the ongoing legal disputes of the past automatically. Also, the company will immediately devote less time to check sources, counterparties, etc. Therefore, it can be assumed that this 5-year-old shift is caused by the inertia of the set according to the last state of trust in the company.

To study the impact of trust on economic performance the most limiting factors are data regarding interpersonal trust gathered in the survey for the World Values Survey, as they are acquired irregularly, in the so-called waves with about five-year pitch, while the individual waves are not covered by the same countries. Data are therefore in the rom of unbalanced panel data limiting its potential for exploring causal link between trust and other monitored variables.

The second problem referred to by Dehley et al. (2011), is the so-called "radius problem" in the context of measuring the level of trust for the country. The problem lies in the fact that the question of whether you believe most people has a big impact on the wideness of respondent's range of "most people". In rich countries is this range wider than, for example, in countries affected by Confucianism.

\section{Acknowledgement}

"Financial health of companies and its importance in the context of supplier-customer relations" supported by Scientific Grant Agency VEGA (Grant agreement number 1/0978/16).

\section{References}

Algan, Y.; Cahuc, P. 2013. Trust and Growth, Annual Review of Economics 5: 521-549.

Arrow, K. 1972. Gifts and Exchanges, Philosophy and Public Affairs 1: 343-362.

Bacik, R.; Gavurova, B.; Fedorko, I. 2015. The Analysis of the Impact of Selected Marketing Communication Factors on the Online Consumer Behavior, Journal of Applied Economic Sciences 10 (7): 999-1004.

Barro, R. 1991. Economic Growth in a Cross-Section of Countries, The Quarterly Journal of Economic 106: 407-443.

Belás, J.; Demjan, V.; Habánik, J.; Hudáková, M.; Sipko, J. 2015. The business environment of Small and medium-sized companies in selected regions of the Czech Republic and Slovakia, E+M. Ekonomie a Management, 18 (1), pp. 95-110.

Bhattacharya, R.; Devinney, T. M.; Pillutla, M. M. 1998. A formal model of trust based on outcomes, Academy of Management Review 23: 459-472.

Carnevale, D. G.; Weschler, B. 1992. Trust in the public sector: Individual and organizational determinants, Administration and Society 23 (4): 471-494.

Cook, T. E.; Gronke, P. 2001. The Dimensions of Institutional Trust: How Distinct is Public Confidence in the Media? [online], [cited 05 April 2016]. Available from Internet: http://www.reed.edu/ gronkep/papers.html

Cook, J.; Wall, T. 1980. New work attitude measures of trust, organizational commitment and personal need non-fulfillment, Journal of Occupational Psychology 53: 39-52.

Delhey, J.; Newton, K. 2003. Who Trusts? The Origins of Social Trust in Seven Societies, European Studies 5: 93-137.

Deutsch, M. 1973. The resolution of conflict: Constructive and destructive processes, Yale University Press.

Fukuyama, F. 1995. Trust: The Social Virtues and the Creation of Prosperity. Free Press.

Fuschi, D. L.; Tvaronavičienè, M. 2016. A network based business partnership model for SMEs management, Entrepreneurship and Sustainability Issues 3(3): 282-289. http://dx.doi.org/10.9770/jesi.2016.3.3(5)

Gavurová, B.; Štefko, R.; Bačík, R. 2014. The Analysis of Social Services' Structure in a Specific Region and its Significance for Health and Social Policy in Slovakia, Polish Journal of Management Studies 10 (2): 43-53.

Gruning, J. E.; Hon, L. C. 1999. Guidelines for measuring relationships in public relations. [online], [cited 07 May 2016]. Available from Internet: http://www.instituteforpr.com/pdf/1999_guide_measure_relationships.pdf 
Jantoń-Drozdowska, E.; Majewska, M. 2015. Social Capital as a Key Driver of Productivity Growth of the Economy: Across-countries Comparison. Equilibrium. Quarterly Journal of Economics and Economic Policy 10 (4), pp. 61-83, http://dx.doi.org/10.12775/ EQUIL.2015.035

Kac, S. M.; Gorenak, I.; Potocan, V. 2016. The influence of trust on collaborative relationships in supply chains. E a M: Ekonomie a Management 19 (2), pp. 120-131, ISSN 2336-5604 http://doi.org/10.15240/tul/001/2016-2-008

Knack, S.; Keefer, P. 1997. Does Social Capital Havean Economic Payoff? A Cross-Country Investigation, Quarterly Journal of Economics 112 (4): 1251-88.

Laužikas, M.; Dailydaite, S. 2015. Impacts of social capital on transformation from efficiency to innovation-driven business, Journal of Business Economics and Management 16 (1), 37-51 http://doi.org/10.3846/16111699.2012.754374

Luhman, N. 2000. Vertrauen, Stuttgart: Lucius and Lucius.

Mlčoch, L. 2006. Ekonomie di̊věry a společného dobra. Praha: Karolinum.

Newton, K. 1997. Social Capital and Democracy, American Behavioral Scientist 40: 575-586.

North, D. C. 1990. Institutions, Institutional Change and Economic Performance, Cambridge University Press.

Ohlson, M. 1982. The Rise and Decline of Nations: Economic Growth, Stagflation and Social Rigidities, Yale University Press.

Putnam, R. D. 1993. Making Democracy Work: Civic Traditions in Modern Italy, Princeton University Press.

Putnam, R. D. 1995. Bowling Alone: America's Declining Social Capital, Journal of Democracy 6: 65-78.

Putnam, R. D. 2000. Bowling Alone: The Collapse and Revival of American Community, New York: Simon and Schuster.

Roth, F. M. 2007. Social Capital, Trust, and Economic Growth-A Cross-Sectional and Panel Analysis, Dissertation, Universität Göttingen, p.153.

Roth, F. 2009. Does Too Much Trust Hamper Economic Growth? KYKLOS 62 (1): 103-128.

Simionescu, M. 2016. Competitiveness and Economic Growth in Romanian Regions. Journal of Competitiveness, 8 (4), pp 46-60. http://doi.org/10.7441/joc.2015.03.05

Škarpová, L.; Grosová, S. 2015. The Application of Business Network Approach for Small and Medium Enterprises (SME) with regard to their Buying Behavior. Journal of Competitiveness 7 (3), pp. 62-74, ISSN 1804-1728 http://doi.org/10.7441/joc.2015.03.05

Tvaronavičienè, M.; Razminienè, K.; Piccinetti, L. 2015. Cluster efficiency study through benchmarking, Entrepreneurship and Sustainability Issues 3(2): 120-128. http://dx.doi.org/10.9770/jesi.2015.3.2(0)

Uslaner, E. M. 2002. The Moral Foundations of Trust, Cambridge University Press.

Virglerova, Z.; Dobes, K.; Vojtovic, S. 2016. The Perception of the State's Influence on its Business Environment in the SMEs from Czech Republic. Administratie si Management Public, 26 (5), pp. 78-96.

World Values Survey Association. 2009. World Value Survey 1981-2008., Aggregate File Producer: ASEP/JDS Data Archive. Madrid, Spain. Retrieved from: <www.worldvaluessurvey.org >

Whiteley, Paul F. 2000. Economic Growth and Social Capital, Political Studies 48: 443-466.

Williams, B. 1988. Formal Structures and Social Reality, Gambetta, D. (Ed.). Trust: Making and Breaking Cooperative Relations, Oxford: Basil Blackwell.

Zak, P. J.; Knack, S. 2001. Trust and Growth, Economic Journal 111: 295-321. 